Original article

\title{
TRANSDIAPHRAGMATIC LYMPHATIC TRANSPORT OF INTRAPERITONEALLY ADMINISTERED MARKERS IN RATS
}

\author{
M. PASIERBEK, M. LEGIERSKA, M. BULINSKI \& K. SLUSARCZYK
}

Department of Anatomy, Medical University of Silesia in Katowice, Zabrze, Poland

\begin{abstract}
Summary
Pasierbek, M., M. Legierska, M. Bulinski \& K. Slusarczyk, 2016. Transdiaphragmatic lymphatic transport of intraperitoneally administered markers in rats. Bulg. J. Vet. Med., 19, No 2, 137-144.

Experimental studies were undertaken, aiming at evaluation of lymphatic drainage from the peritoneal cavity to lymph nodes of the cranial mediastinum in rats. The study made use of 11 adult male Wistar rats. For examination of lymphatic structures drawing ink and FITC-dextran, administered intraperitoneally, were used. Due to lack of unambiguous terminology quoted in the literature with regard to the lymph nodes of the rats' cranial mediastinum, the authors' own nomenclature was suggested to introduce the notions of the medial mediastinal lymph node and the lateral mediastinal lymph node. After intraperitoneal markers' injection in each case bilateral lymphatic vessel was observed, emptying to the mediastinal nodes of the proper side. The inflow of the markers was observed in both medial mediastinal nodes or in both lateral mediastinal nodes or in all lymph nodes of the cranial mediastinum. We can conclude that the lymph outflow from the peritoneal cavity to the lymph nodes of the cranial mediastinum is always bilateral.
\end{abstract}

Key words: lymphatic drainage, mediastinal lymph nodes, peritoneal cavity, rats

\section{INTRODUCTION}

The lymphatic system and its anatomy was described many times in animals (Barone et al., 1950; Nishida, 1954; Rusznyāk, 1969; Seo, 1981; Popesko, 1992), nevertheless, there is no uniform nomenclature. Despite the ambiguous terminology, for oncological reasons, scientists and physicians performing research into the lymphatic structures are highly concerned especially about the lymph nodes, since their enlargement is always a sign of disease. Even at proper size, following appropriate examination methods, they can prove a valuable source of information about the physiological and pathological processes. Metastases to regional lymph nodes are a universal sign of progression of many malignant neoplasms. The role of lymphatic system in rabbit models for cancer metastasis was decribed by Oshiro (2014). The regional node which is first to receive lymph from the tumour is called the Sentinel Lymph Node (Uren \& Hoefnagel, 2004). No tumorous 
cells found in that node allow for further appropriate diagnostic and therapeutic procedures, giving an opportunity to avoid radical lymphadenectomy (Keshtgar et al., 1999; Parungo et al., 2005). With regard to the possibility of macromolecular compounds' and neoplastic cells' transport via lymphatic vessels (Nieweg et al., 2000; Parungo et al., 2007; Shibata et al., 2007), experimental studies were undertaken, aiming at evaluation of lymphatic drainage from the peritoneal cavity to lymph nodes of the cranial mediastinum in rats.

\section{MATERIALS AND METHODS}

The study made use of 11 adult male Wistar rats weighing $350-400 \mathrm{~g}$, supplied by the Center for Experimental Medicine of the Medical University of Silesia in Katowice. Approval no. 48/2010 of the Local Ethical Committee and permission no. $5 / 2010$ of the Dean of the Faculty of Medicine in Zabrze were obtained.

Experiments were conducted after intraperitoneal $4 \%$ chloral hydrate (Sigma, USA) injection at a dose of $400 \mathrm{mg} / \mathrm{kg}$ body weight. Intubation and artificial respiration (ventilation rate of $70 / \mathrm{min}$ and ventilation volume of $2-2.5 \mathrm{~mL}$ ) with a ventilator for small animals (SAR-830/P) were performed.

For examination of lymphatic structures, 1:1 water suspension of drawing ink (Staedler Mars GmbH \& Co, Germany) (hydrodynamic diameter $20-50 \mathrm{~nm}$ ) and $1 \%$ water solution of fluorescein isothiocyanate dextran 70,000 (Sigma, USA) (FITC-dextran 70,000; hydrodynamic diameter $11 \mathrm{~nm}$ ) were used. Observations were done with a stereomicroscope (Nikon SMZ800), after ink injection in white light and after FITC-dextran injection in violet-blue light (rousing filter
Zeiss B.G.3/2, barrage filter Zeiss O.G.1+GG9).

The animals were divided into two subgroups: Subgroup A counting 5 rats suspension of ink was administered and subgroup B counting 5 rats - FITC-dextran 70,000 was administered.

After anesthesia, $2 \mathrm{~mL}$ of each marker were injected intraperitoneally by puncture of the left lower abdominal quadrant. Artificial ventilation was initiated and opening of the thorax was performed by excision of its ventral wall. Observations followed for two hours after ink injection and for 90 minutes after FITC injection.

One rat was used as control. The procedure was identical to that described above, except for the marker's injection; $0.9 \% \mathrm{NaCl}$ was administered instead of the tracer.

After the procedures the animals underwent euthanasia by bleeding from the thoracic aorta cut above the diaphragm.

\section{RESULTS}

Taking into consideration the lack of unambiguous terminology quoted in the literature with regard to the lymph nodes of the rats' cranial mediastinum, the authors' own nomenclature was suggested to introduce the notions of the medial mediastinal lymph node and the lateral mediastinal lymph node. Medial mediastinal nodes are situated symmetrically and medially to vena cava superior of the proper side, whereas lateral mediastinal nodes are positioned laterally to each vena cava superior and asymmetrically to each other (the right lateral lymph node more dorsally than the left one). In eight $(80 \%)$ rats configuration of one medial and one lateral mediastinal lymph node on each side was observed. In one $(10 \%)$ rat, three mediastinal nodes on each side were shown 
and in one case $(10 \%)$ absence of lateral mediastinal lymph node was noticed.

After intraperitoneal markers' administration, bilateral lymphatic plexus on the diaphragm's cranial surface was observed (Fig. 1 and 2). From each plexus a lym- phatic vessel rose, running cranially on the internal surface of the dorso-lateral part of the thoracic wall (Fig. 3). Each vessel emptied to the mediastinal nodes of the proper side (Fig. 4, Table 1). Thus, in each case, bilateral inflow of the marker

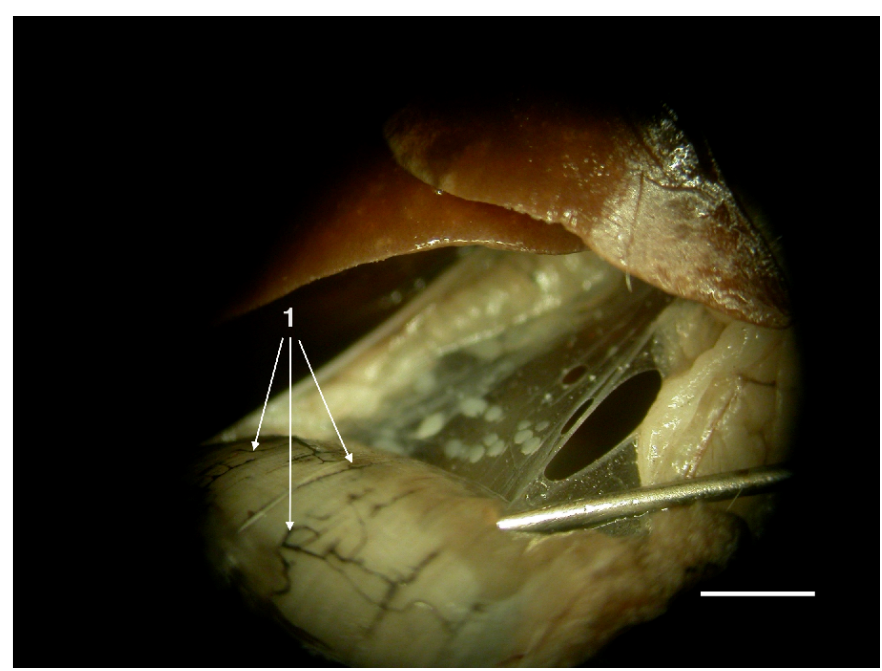

Fig. 1. Right lymphatic plexus (1) after ink injection to the peritoneal cavity (the tool indicates right diaphragmatic dome); bar $=3 \mathrm{~mm}$.

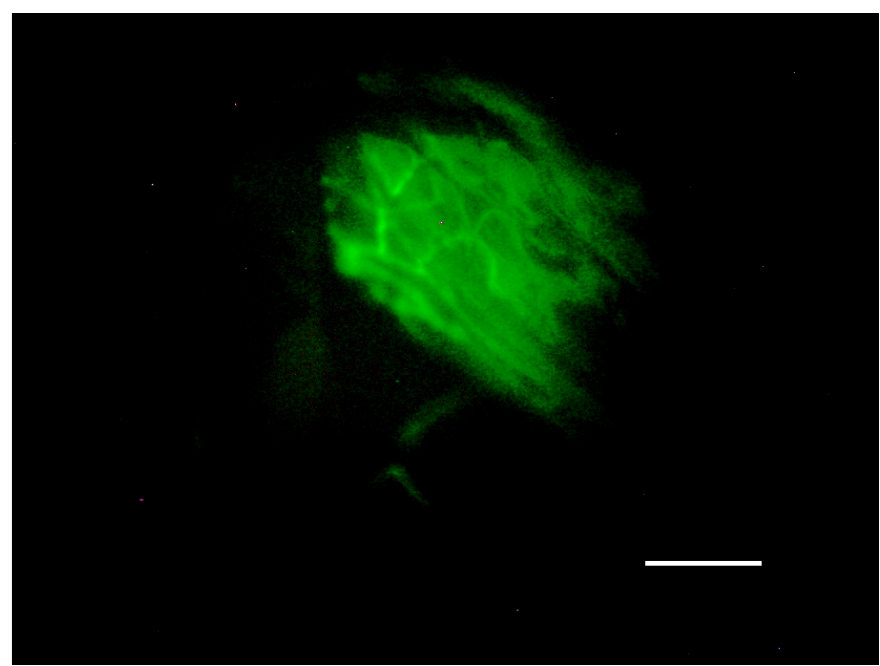

Fig. 2. Left lymphatic plexus after FITC-dextran (fluorescein isothiocyanate dextran) injection to the peritoneal cavity; bar $=3 \mathrm{~mm}$. 
Transdiaphragmatic lymphatic transport of intraperitoneally administered markers in rats

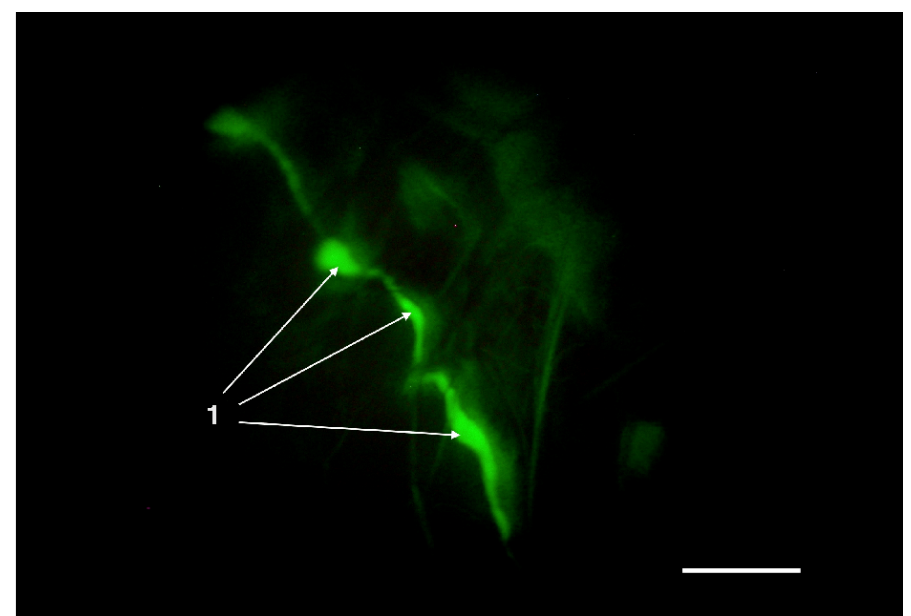

Fig. 3. Lymphatic vessel leading to the left lateral mediastinal lymph node, after FITC-dextran injection to the peritoneal cavity. Arrows indicate lymphangions; bar $=3 \mathrm{~mm}$.

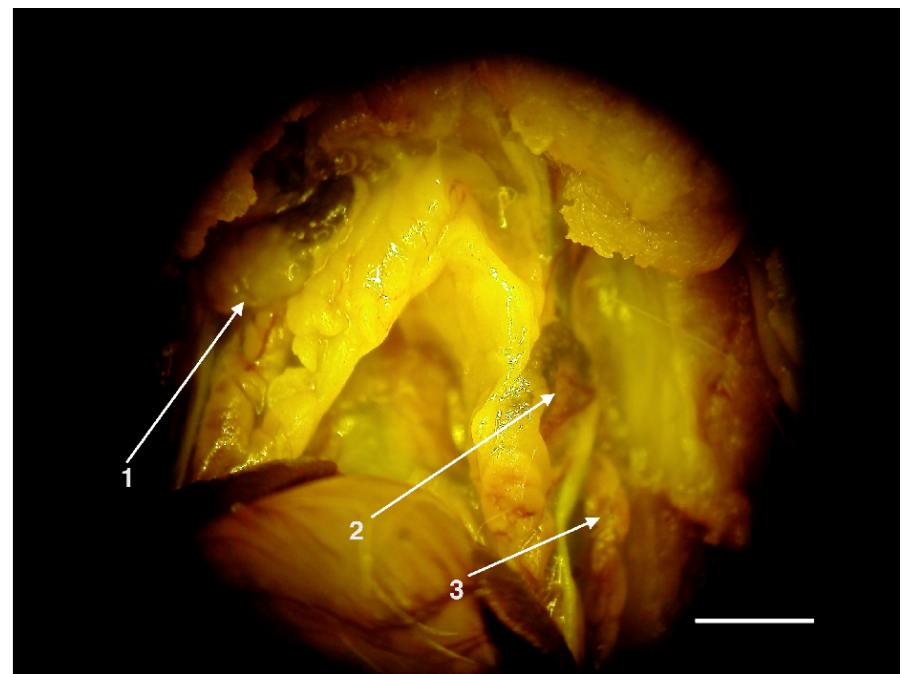

Fig. 4. Lymph nodes of the anterior mediastinum after intraperitoneal ink administration; 1 - Right medial mediastinal lymph node (marker present); 2 - Left medial mediastinal lymph node (marker present); 3 - Left lateral mediastinal lymph node (marker absent); bar=3 $\mathrm{mm}$.

to lymph nodes of the cranial mediastinum was observed. Additionally, one case revealed the lymphatic vessels running on the internal surface of the sternum to mediastinal lymph nodes.

The pattern of the lymph outflow from the peritoneal cavity to the lymph nodes of the cranial mediastinum is shown below (Fig. 5).

\section{DISCUSSION}

Numerous data in the literature refer to the possibility of reaching mediastinal nodes by intraperitoneally administered substan- 
Table 1. Markers injection to the peritoneal cavity

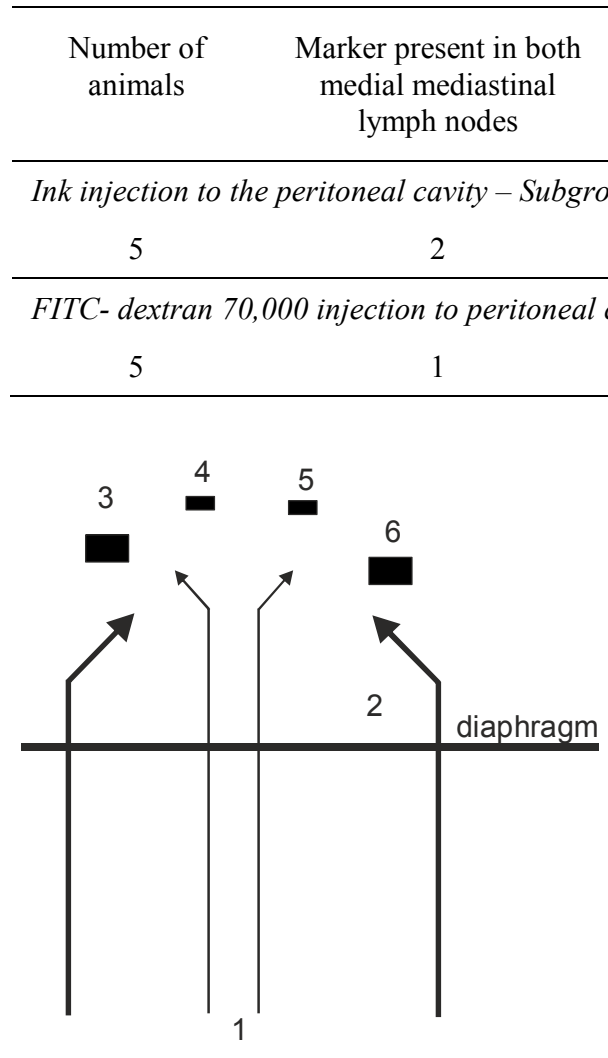

Fig. 5. The pattern of the lymph outflow from the peritoneal cavity to the lymph nodes of the anterior mediastinum of both sides. Thicker arrows illustrate the main flow from the peritoneal cavity to the mediastinal lymph nodes, whereas thinner ones illustrate the route along the internal thoracic vessels. 1 - Peritoneal cavity; 2 - Thoracic cavity; 3 - Right lateral mediastinal lymph node; 4 - Right medial mediastinal lymph node; 5 - Left medial mediastinal lymph node; 6 - Left lateral mediastinal lymph node.

ces (Zakaria et al., 1996; Fritz \& Waag, 1999; Parungo et al., 2007; Shibata et al., 2007). Some authors claim that the lymph outflow from the peritoneum to nodes situated in the thorax is the main route and appears more important than outflow to the intraabdominal nodes (Fritz \& Waag, 1999). Some have even suggested that thoracic lymph nodes are the first to receive the lymph inflow (Abernethy et al., 1991), this, however, is denied by others (Parungo et al., 2007). Lymph outflow from the peritoneum to the mediastinal lymph nodes has been documented in many species (Abernethy et al, 1991; Fritz \& Waag, 1999).

Shibata et al. (2007) describes four types of ink outflow from the peritoneal cavity. The first is along internal thoracic vessels, the second leads through the lymphatic vessels along the phrenic nerves and the third runs via the lymphatic trunk, running on the dorso- lateral part of the thoracic wall. These routes lead to the lymph nodes of the cranial mediastinum. The last one, through the cisterna chili, leads to the thoracic duct. According to Ezaki et al. (2004), three types of outflow exist - anterior (parasternal), posterior (dorsal) and via the thoracic duct (least important). The first leads to the parathymic lymph nodes (medial mediastinal lymph nodes in the present study), the second to the mediastinal nodes (lateral mediastinal lymph nodes in the present study). In our study, we observed the main outflow through vessels running on the internal surface of the dorso- lateral part 
of the thoracic wall, which refers to the third route quoted in Shibata et al. (2007) work and the second one as defined by Ezaki et al. (2004). In one case the outflow took place on the internal surface of the sternum (referred to as the first route by both Shibata et al. (2007) and Ezaki et al. (2004).

Injecting HSA800 (Human Serum Albumin) and QDs (quantum dots) tracers into the peritoneal cavity, Parungo et al. (2007) observed the lymph outflow from the peritoneum to the lymph nodes of the cranial mediastinum, as well as to the thoracic duct via intraabdominal lymph nodes. Parungo et al. (2007) proved that after bowel resection (all abdominal lymph nodes were intact), the marker administered intraperitoneally is captured by the mediastinal lymph nodes. Following such observation, the authors concluded that lymph vessels of the visceral peritoneum led the lymph from the peritoneal cavity via particular groups of abdominal lymph nodes to the thoracic duct, whereas from the parietal peritoneum, the lymph flowed to lymph nodes of the cranial mediastinum (the diaphragmatic peritoneum differs in its structure from other parts of the parietal peritoneum, and is probably the only place to absorb the macromolecular compounds, colloids, corpuscular substances or cells to the lymphatic vessels).

Tilney (1971) reports the marker's uptake from the peritoneal cavity only to the parathymic lymph nodes (referred to as the medial mediastinal nodes in the present work), while Takahashi \& Patrick (1987) observed the presence of the marker in both parathymic nodes and only the left mediastinal lymph node (referred to as lateral mediastinal lymph node in the present work). In our study we observed that the lymph outflow from the peritoneal cavity to the lymph nodes of the cranial mediastinum was always bilateral (Table 1). Injecting Tc-99m albumin nanocolloid intraperitoneally, Shih et al. (1993) observed the symmetrical uptake of the marker in the mediastinal lymph nodes. According to Rusznyāk et al. (1969) after intraperitoneal blood administration, the number of erythrocytes was higher in the right lymphatic duct than in the thoracic duct. Such observations were made in dogs, rabbits and guinea-pigs, while results received in cats and rats were contradictory.

As indicated from the data above, the authors do generally agree on the bilateral marker's capture by the lymph nodes of the cranial mediastinum. The differences refer mainly to the symmetry of the uptake or the number of lymph nodes involved.

Translocation of the peritoneal fluid components in the lymph flowing in the thoracic duct is the result of the previous transport of such components to the abdominal lymphatics and through abdominal lymph nodes, therefore evading the lymph nodes situated in the thorax. While it has been accepted that in every case of lymph drainage's examination from the peritoneal cavity, the marker's capture by the lymph nodes situated in the thorax is also observed, it is always the result of activation of the previously mentioned 'anterior and posterior lymphatic route'.

It is likely that the respiration movements, the muscular tonus or body position may influence the current activity of a given lymphatic route. In quadrupeds, due to the body position, the peritoneal fluid gathers on the ventral side of the body, and therefore the anterior lymphatic route is most likely to be activated first. Moreover, interspecies, interstrain or individual differences may play an important role (Shibata et al., 2007). 


\section{ACKNOWLEDGEMENTS}

This work was partially supported by the Medical University of Silesia in Katowice [grant number RDLD-640/21/2011]. The authors would like to thank Wojciech Korlacki, MD and Wojciech Skrzypiec, MD for helpful discussion, and Dr Andrzej Kuropatnicki and colleagues for assistance with the manuscript.

\section{REFERENCES}

Abernethy, N. J., W. Chin, J. B. Hay, H. Rodela, D. Oreopoulos \& MG. Johnston, 1991. Lymphatic drainage of the peritoneal cavity in sheep. American Journal of Physiology, 260, F353-358.

Barone, R., Bertrand, M., Desenclos, R., 1950. Recherches anatomiques sur les ganglions lymphatiques des petits rongeurs de laboratoire. Revue de Médecine Vétérinaire, 101, 423.

Ezaki, T., K. Kuwahara, S. Morikawa, K. Matsuno \& N. Sakaguchi, 2004. Characterization of adjuvant-induced rat lymphagiomas as a model to study the lymph drainage from abdominal cavity. Japanese Journal of Lymphology, 27, 1-7.

Fritz, D. L \& D. M. Waag, 1999. Transdiaphragmatic lymphatic transport of intraperitoneally administered marker in hamsters. Laboratory Animal Science, 49, 522-529.

Keshtgar, M. R. S., W. A. Waddington, S. R. Lakhani \& P. J. Ell, 1999. The Sentinel Node in Surgical Oncology. Springer Verlag, Berlin Heidelberg.

Nieweg, O. E., R. Essner, D. S. Reintgen \& J. F. Thompson, 2000. Lymphatic Mapping and Probe Applications in Oncology. Marcel Dekker, Inc, New York Basel.

Nishida, K., 1954. About the lymphatic system in rabbits. Kumamoto Igakkai Zasshi, 28, 295-318.

Oshiro, H., 2014. The role of the lymphatic system in rabbit models for cancer metastasis research: A perspective from com- parative anatomy. Okajimas Folia Anatomica Japonica, 91, 25-28.

Parungo, Ch. P., Y. L. Colson, S. W. Kim, S. Kim, L. H. Cohn, M. G. Bawendi \& J. V. Frangioni, 2005. Sentinel lymph node mapping of the pleural space. Chest, 127, 1799-1804.

Parungo, Ch. P., D. I. Soybel, Y. L. Colson, S. W. Kim, S. Ohnishi, A. M. DeGrand, R. G. Laurence, E. G. Soltesz, F. Y. Chen, L. H. Cohn, M. G. Bawendi \& J. V. Frangioni, 2007. Lymphatic drainage of the peritoneal space: A pattern dependent on bowel lymphatics. Annals of Surgical Oncology, 14, 286-298.

Popesko, V., V. Rajtová \& J. Horák A, 1992. Colour Atlas of the Anatomy of Small Laboratory Animals. Vol. II. Rat, Mouse, Hamster. Wolfe Publishing Ltd., London.

Rusznyāk, I., M. Földi \& G. Szabo, 1969. Lymphologie. Physiologie und Pathologie der Lymphgefasse und des lymphkreislaufes. Akademiai Kiado, Budapest.

Seo, S., 1981. Anatomical study of the lymphatic system in rats. Tokyo Jikeikai Medical Journal, 96, 642-662.

Shibata, S., S. Yamaguchi, M. Kaseda, N. Ichihara, T. Hayakawa \& M. Asari, 2007. The time course of lymphatic routes emanating from the peritoneal cavity in rats. Anatomia, Histologia, Embryologia, 36, 78-82.

Shih, W. J., J. J. Coupal \& H. L. Chia, 1993. Communication between peritoneal cavity and mediastinal lymph nodes demonstrated by Tc-99m albumin nanocolloid intraperitoneal injection. Proceedings of the $\mathrm{Na}$ tional Science Council, Republic of China. Part B, 17,103-105.

Takahashi, S. \& G. Patrick, 1987. Patterns of lymphatic drainage to individual thoracic and cervical lymph nodes in the rat. Laboratory Animals, 21, 31-34.

Tilney, N. L., 1971. Patterns of lymphatic drainage in the adult laboratory rat. Journal of Anatomy, 109, 369-383. 
Transdiaphragmatic lymphatic transport of intraperitoneally administered markers in rats

Uren, R. F. \& C. A. Hoefnagel, 2004. Lymphoscintigraphy. In: Textbook of Melanoma, eds J. F. Thompson, D. M. Morton, B. B. R. Kroon, London, UK, chapter 30 , pp. 339-364.

Zakaria, E. R., O. Simonsen, A. Rippe \& B. Rippe, 1996. Transport of tracer albumin from peritoneum to plasma: role of diaphragmatic, visceral, and parietal lymphatics. American Journal of Physiology, 270, H1549-H1556.

Paper received 09.02.2015; accepted for publication 08.05.2015

\section{Correspondence:}

Michal Pasierbek

Department of Anatomy,

Medical University of Silesia in Katowice,

Jordana 19, 41-808 Zabrze, Poland.

Department of Pediatric Surgery,

Medical University of Silesia in Katowice,

3-go Maja 13-15,

41-800 Zabrze, Poland.

Tel. 48500089727

e-mail: michal.pasierbek@sum.edu.pl 